IZA DP No. 4544

Impacts of Labor Taxation with Perfectly and Imperfectly Competitive Domestic Labor Markets under Flexible Outsourcing

Erkki Koskela

November 2009 


\title{
Impacts of Labor Taxation with Perfectly and Imperfectly Competitive Domestic Labor Markets under Flexible Outsourcing
}

\author{
Erkki Koskela \\ University of Helsinki \\ and IZA
}

Discussion Paper No. 4544

November 2009

IZA

P.O. Box 7240

53072 Bonn

Germany

Phone: +49-228-3894-0

Fax: +49-228-3894-180

E-mail: iza@iza.org

Any opinions expressed here are those of the author(s) and not those of IZA. Research published in this series may include views on policy, but the institute itself takes no institutional policy positions.

The Institute for the Study of Labor (IZA) in Bonn is a local and virtual international research center and a place of communication between science, politics and business. IZA is an independent nonprofit organization supported by Deutsche Post Foundation. The center is associated with the University of Bonn and offers a stimulating research environment through its international network, workshops and conferences, data service, project support, research visits and doctoral program. IZA engages in (i) original and internationally competitive research in all fields of labor economics, (ii) development of policy concepts, and (iii) dissemination of research results and concepts to the interested public.

IZA Discussion Papers often represent preliminary work and are circulated to encourage discussion. Citation of such a paper should account for its provisional character. A revised version may be available directly from the author. 
IZA Discussion Paper No. 4544

November 2009

\section{ABSTRACT}

\section{Impacts of Labor Taxation with Perfectly and Imperfectly Competitive Domestic Labor Markets under Flexible Outsourcing*}

What are the impacts of labor tax reform on wage setting and employment to keep the relative tax burden per low-skilled and high-skilled workers constant in the case of heterogenous domestic labor markets, i.e. imperfect competition in low-skilled labor and perfect competition in high-skilled labor in the presence of outsourcing? A higher degree of tax progression by raising the wage tax and the tax exemption for the low-skilled workers will decrease the wage rate and increase labour demand of low-skilled workers, whereas it will decrease (increase) employment of high-skilled workers in CES utility function when the elasticity of substitution between consumption and leisure is higher (lower) than one. A higher degree of wage tax progression for the high-skilled worker will have no effect on the highskilled wage in the presence of CES and C-D utility function so this will have no total employment effects.

JEL Classification: E24, H22, J21, J31, J51

Keywords: flexible outsourcing, dual labor market, impacts of labour taxation

Corresponding author:

Erkki Koskela

Department of Economics

University of Helsinki

P.O. Box 17 (Arkadiankatu 17)

00014 Helsinki

Finland

E-mail: erkki.koskela@helsinki.fi

\footnotetext{
* I thank the Academy of Finland (grant No. 1217622) for financial support.
} 


\section{Introduction}

European Welfare States are characterized by dual labour markets. Unskilled workers are typically unionized, while skilled workers often negotiate on their wages individually, and, thus, face more competitive wage formation. ${ }^{1}$ Historically, labour unions have been able to push for relatively high wages of unskilled workers, at the cost of a higher unemployment in Continental Europe than in the United States. During the late $20^{\text {th }}$ century and this decade, globalization has put the European welfare model under increasing pressure. Wage differences across countries constitute a central explanation for the increasing dominant business practice of international outsourcing across a wide range of industries (see e.g. Sinn (2007) for an overview and Stefanova (2006)) concerning the East-West dichotomy of outsourcing).

Outsourcing can take two alternative forms. Firms may write long-term contracts that fix the amount of outsourcing before the trade union sets the wage, i.e. strategic outsourcing, or alternatively firms may be flexible enough to decide upon the amount of outsourcing activity simultaneously with domestic labour demand after the domestic wage is set by the trade union.

While there is a large literature on international outsourcing, only a few contributions have studied the various effects of wage taxation in its presence. Koskela and Schöb (2009) analyze in the case of monopoly trade union the impacts of labour tax policy reforms in the presence of both strategic and flexible outsourcing when domestic labour is homogeneous. This paper opens a new research theme by analyzing the effects of wage taxation with flexible international outsourcing when the domestic labour market is heterogeneous so that labor markets are imperfectly competitive in the case of low-skilled workers when monopoly trade union decides the wage rate of low-skilled workers, and perfectly competitive in the case of high-

We use the term unskilled workers as a shorthand notation to denote workers with less qualifications than skilled workers. In practise, these may also be skilled but just less skilled workers. 
skilled workers os that the high-skilled wage adjust to equalize labor demand and labor supply by also assuming CES-utility function which depends on the elasticity of substitution between consumption and leisure for high-skilled workers. We assume for simplicity that there is the representative firm to allow for different labour market situation. ${ }^{2}$

We find that in the presence of flexible outsourcing both in the case of highskilled workers' CES and in the case of C-D utility function in competitive labor market equilibrium (a) the high-skilled wage depends negatively on the low-skilled wage, whereas (b) the high-skilled wage depends positively (negatively) on the wage tax when the elasticity of substitution between consumption and leisure is higher (lower ) than one, whereas (c) the high-skilled wage depends negatively (positively) on the tax exemption when the elasticity of substitution between consumption and leisure is higher (lower) than one, while the high-skilled wage is independent of tax parameters under C-D utility function. Both in the case of highskilled workers' CES and C-D utility function in competitive labor market equilibrium higher outsourcing wage and higher outsourcing cost will increase the wage for the low-skilled labor because the wage elasticity of the low-skilled labor will decrease and these will decrease the wage for the high-skilled labor.

A higher unskilled wage tax rate will increase the wage for the low-skilled labour and decrease the wage for high-skilled labour and the higher unskilled wage tax exemption will decrease the wage for the low-skilled labour and will increase the wage for the high-skilled labour. Similar qualitative effects arise in the absence of outsourcing. In terms of labor tax reform (a) a higher degree of tax progression by raising the wage tax and the tax exemption for the low-skilled workers to keep the relative burden per low-skilled worker constant will decrease the wage rate and increase labour demand of low-skilled workers, whereas (b) it will decrease (increase) employment of high-skilled workers in CES utility function when the elasticity of substitution between consumption and leisure is higher (lower) than one,

2 Other research topic is to focus the role of heterogeneous firms to study the interaction between wage bargaining and e.g. foreign direct investment (see e.g. Eckel and Egger (2900) about this analysis but in the absence of labor market policy reforms). 
(c) A higher low-skilled wage tax rate will increase the wage for the low-skilled labour and decrease the wage for high-skilled labour and the higher low-skilled wage tax exemption will decrease the wage for the low-skilled labour and will increase the wage for the high-skilled labour. Similar qualitative effects arise in the absence of outsourcing. In terms of labor tax reform (a) a higher degree of tax progression by raising the wage tax and the tax exemption for the low-skilled workers to keep the relative burden per low-skilled worker constant will decrease the wage rate and increase labour demand of low-skilled workers, whereas (b) it will decrease (increase) employment of high-skilled workers in CES utility function when the elasticity of substitution between consumption and leisure is higher (lower) than one, (c) while it will have no effect on employment of high-skilled workers in the case of C-D utility function of high-skilled workers.

Finally, a higher degree of wage tax progression for the high-skilled worker , keeping the relative tax burden per high-skilled worker constant, will have no effect on the high-skilled wage in the presence of CES and C-D utility function. Because there are no effect of high-skilled wage tax progression on high-skilled and lowskilled wage in the case of different tax parameters compared with low-skilled workers, there is no employment effects in this case.

We proceed as follows: Section II presents the time sequence of the decisions regarding some policy issues associated with labour taxes, wage setting for domestic low-skilled workers, labour demand for domestic high-skilled and low-skilled workers, outsourcing and wage setting for skilled workers. We study the segmented domestic labor demand for heterogeneous work force and outsourcing decision and wage formation of high-skilled workers due to market equilibrium under labor taxation in section III. Wage formation by the monopoly labour union for low-skilled workers under a linearly progressive wage tax levied on workers is analyzed in section IV. In section $\mathrm{V}$ we study the impacts of both low-skilled skilled wage progression and high-skilled wage progression on wage setting and employment of both types of workers. Finally, we summarize conclusions in section VI. 


\section{Basic Framework}

We analyze a model with heterogeneous domestic workers and international outsourcing. The production combines labor services by high-skilled workers and low-skilled workers. Low-skilled labor services can be provided either by the firm's own workers, or obtained from abroad through international outsourcing. We assume that the firms may be flexible enough to decide upon the amount of outsourcing activity only after the wage is set by the trade union. Skaksen (2004) has analyzed the implications of outsourcing for wage setting and employment under imperfectly competitive labor markets in terms of both potential (non-realized) and realized international outsourcing. Also he analyzes flexible outsourcing, but in homogenous domestic labor markets. Also Braun and Scheffel (2007) have developed a simple two-stage game between a monopoly union and a firm by assuming that the labor union sets wages before the firms decide on the degree of outsourcing.

The time sequence for this case is described by Figure 1.

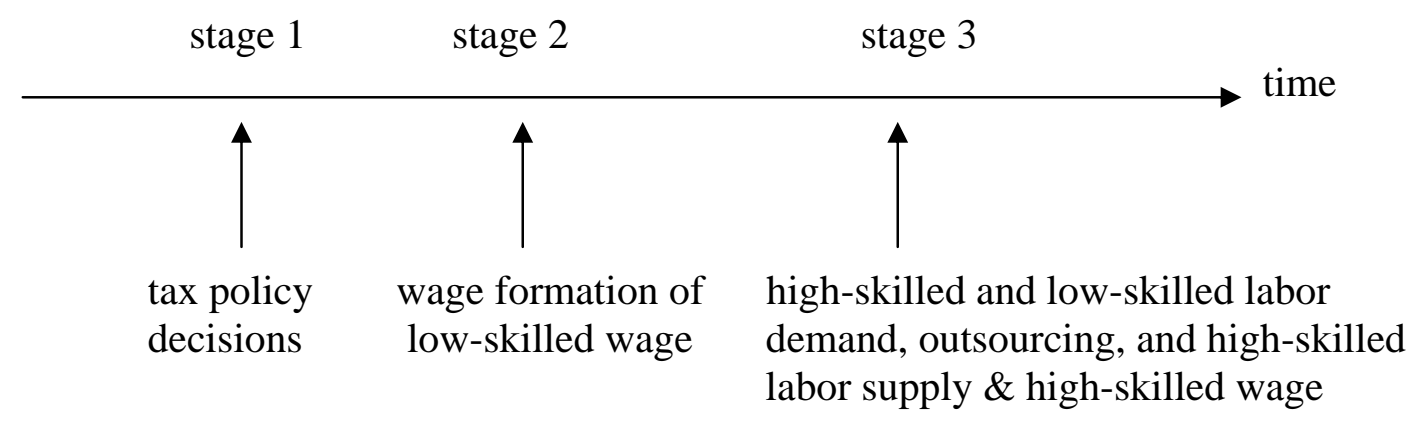

Figure 1: Time sequence of decisions

The government sets its policy at stage 1. At stage 2 conditional on policy choices by the government, the labor union determines the wage for the low-skilled workers by taking into account how this affects the demand for labor and outsourcing by the firms. We assume that there are many industries, so that each labor union represents only a small fraction of the total labor force. At stage 3, firms decide on 
domestic employment and international outsourcing. The wages of the high-skilled labor adjust to equalize labor demand and labor supply. The decisions at each stage are analyzed by using backward induction.

\section{Labor Demand, Outsourcing Decision and High-Skilled Wage Formation}

\subsection{High-Skilled and Low-Skilled Labor Demand and Outsourcing}

At the last stage, the firm decides on the high-skilled labor demand $H$, the low-skilled labor demand $L$ and outsourcing $M$ in order to maximize the profit function

$$
\underbrace{\operatorname{Max}}_{(H, L, M)} \pi=F(H, L, M)-w_{H} H-w_{L} L-w_{M} M-g(M)
$$

((here $w_{L}$ is the wage for low-skilled labor, $w_{H}$ is the wage for high-skilled labor, and $w_{M}$ wage of outsourcing. We assume that while some activities are easy to outsource, some other activities are more costly to outsource. Therefore, the marginal cost of outsourcing increases in the scope of activities to outsource. To capture this effect we model the acquisition of $M$ units of the outsourced los-killed labor input to require an irreversible investment $g(M)=0,5 c M^{2}$ with $g^{\prime}(M)=c M>0$ and $g^{\prime \prime}(M)=c>0$. This captures the idea that firms make irreversible investment in the establishment of networks of suppliers in the relevant low-wage countries.

We follow Koskela and Stenbacka (2009) by assuming a Cobb-Douglas-type production function with decreasing returns to scale with three labour inputs, i.e. $F(H, L, M)=\left[H^{a}(L+\gamma M)^{1-a}\right]^{\rho}$, where the parameters $\rho$ and $a$ are assumed to 
satisfy: $0<\rho<1$ and $\frac{1}{2}<a<1 .^{3}$ This latter specification means that the marginal productivity of the high-skilled labor is higher than that of the low-skilled labor. The parameter $\gamma>0$ captures the productivity of the outsourced low-skilled labor input relative to the domestic low-skilled labor input. The marginal products of highskilled labor, low-skilled labor and outsourcing are: $F_{H}=\rho F^{\rho-1} a H^{a-1}(L+\gamma M)^{1-a}=\rho a F / H, F_{L}=\rho(1-a) F /(L+\gamma M)$, and $F_{M}=\gamma F_{L}$. The outsourced low-skilled labor input affects the marginal products of the domestic high-skilled and low-skilled labor inputs as follows:

$F_{H M}=\gamma F_{H L}=\frac{\rho^{2} a(1-a) \lambda}{H(L+\gamma M)} F>0$ and $F_{L M}=-\frac{\rho(1-a) \gamma}{(L+\gamma M)^{2}} F[1-\rho(1-a)]<0$.

Thus, for this production function the domestic high-skilled labor input and the outsourced labor input are complements, whereas the low-skilled domestic labor input and the outsourced labor input are substitutes in terms of the marginal product effects of outsourcing. Also one can calculate from the production function that the domestic high-skilled and low-skilled labors are complements, i.e. $F_{H L}>0$. Given the wages, the outsourcing cost function and the outsourcing tax parameter the firstorder conditions characterizing the domestic high-skilled and low-skilled labor demands and outsourcing are

$$
\begin{aligned}
& \pi_{H}=\frac{\rho a}{H} F-w_{H}=0, \\
& \pi_{L}=\frac{\rho(1-a)}{(L+\gamma M)} F-w_{L}=0,
\end{aligned}
$$

3 Ethier (2005) has introduced a partly related Cobb-Douglas aggregate production function, where domestic low-skilled labor and outsourcing are substitutes and domestic high-skilled labor and outsourcing are complements, to analyze the decision between international outsourcing and in-house production in the analysis of the effect of globalization on the skill premium. 


$$
\pi_{M}=\frac{\rho(1-a) \gamma}{(L+\gamma M)} F-w_{M}-c M=0
$$

These first-order conditions imply the following relationship between the highskilled labor $(H)$ and the low-skilled labor inclusive of outsourcing $(L+\gamma M)$

$$
H=\frac{w_{L}}{w_{H}} \frac{a}{1-a}(L+\gamma M) .
$$

Using (2b) and (2c) we have

$$
M^{*}=\frac{\left(\gamma w_{L}-w_{M}\right)}{C}
$$

where $M_{w_{L}}^{*}, M_{\gamma}^{*}>0$, and $M_{c}^{*}, M_{w_{M}}^{*}<0$. According to (4) the higher low-skilled domestic wage rate, and the higher productivity of outsourced labor input will increase outsourcing, while the higher outsourcing wage and the higher outsource cost will decrease flexible outsourcing. In the case of production function $F(H, L, M)=\left[H^{a}(L+\gamma M)^{1-a}\right]^{\rho}$ outsourcing elasticities have the following findings: $\quad \frac{M_{w_{l}}^{*} w_{L}}{M^{*}}=\frac{M_{\gamma_{l}}^{*} \gamma_{L}}{M^{*}}=\eta_{M}^{f}=\frac{\gamma w_{L}}{\left(\gamma w_{L}-w_{M}\right)}=\frac{\gamma w_{L}}{c M^{*}}>1, \quad-\frac{M_{c}^{*} c}{M^{*}}=1 \quad$ and

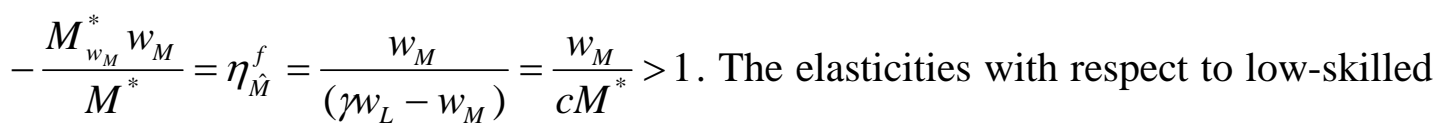
wage, productivity of outsourced labor input, and outsourcing wage in the presence of outsourcing are higher than one. Higher low-skilled wage will decrease these elasticities, i.e. $\frac{\partial \eta_{M}^{f}}{\partial w_{L}}=-\frac{w_{M} \gamma}{\left(\gamma w_{L}-w_{M}\right)^{2}}<0$ and $\frac{\partial \eta_{\hat{M}}^{f}}{\partial w_{L}}=-\frac{w_{M} \gamma}{\left(\gamma w_{L}-w_{M}\right)^{2}}<0$, and higher outsourcing wage will increase these wage elasticities, i.e. $\frac{\partial \eta_{M}^{f}}{\partial w_{M}}=\frac{w_{L} \gamma}{\left(\gamma w_{L}-w_{M}\right)^{2}}>0$ 
and $\frac{\partial \eta_{\hat{M}}^{f}}{\partial w_{M}}=\frac{w_{L} \gamma}{\left(\gamma w_{L}-w_{M}\right)^{2}}<0$. Substituting the RHS of (3) for $H$ into (2b) $\rho(1-a) H^{\rho a}(L+\gamma M)^{\rho(1-a)-1}=w_{L}$ gives $\quad(1-a)\left(\frac{w_{L}}{w_{H}}\right)^{\rho a}\left(\frac{a}{1-a}\right)^{\rho a}(L+\lambda M)^{\rho-1}=\rho^{-1} w_{L}$ so that the low-skilled labor demand can be expressed as

$$
L^{*}=m w_{L}^{-\varepsilon_{L}^{L}} w_{H}^{-\varepsilon_{H}^{L}}-\gamma M^{*}=m w_{L}^{-\varepsilon_{L}^{L}} w_{H}^{-\varepsilon_{H}^{L}}-\gamma\left(\frac{\gamma w_{L}-w_{M}}{c}\right)
$$

where $m=\left[\rho a^{a \rho}(1-a)^{1-a \rho}\right] \frac{1}{1-\rho}>0, \varepsilon_{L}^{L}=\frac{1-\rho a}{1-\rho}>1$ and $\varepsilon_{H}^{L}=\frac{\rho a}{1-\rho}>0$. These are higher with decreasing returns to scale. According to (5), a more extensive outsourcing activity due to a lower outsourcing cost will decrease the low-skilled labor demand, which lies in conformity with empirical evidence. ${ }^{4}$ Moreover, higher outsourcing wage will increase the low-skilled labor demand, i.e. $L_{t}^{*}=\frac{\gamma}{c}>0$. In the presence of outsourcing the wage elasticities of the low-skilled labor, $-\left.\frac{L_{w_{L}}^{*} w_{L}}{L^{*}}\right|_{M>0}$ and $-\left.\frac{L_{w_{H}}^{*} w_{H}}{L^{*}}\right|_{M>0}$, can be written as follows

$$
\eta_{L}^{f}=\varepsilon_{L}^{L}\left(1+\gamma \frac{M^{*}}{L^{*}}\right)+\frac{\gamma}{L^{*}}\left(M^{*}+\frac{w_{M}}{c}\right)=\varepsilon_{L}^{L}+\frac{\gamma}{L^{*}}\left(\left(1+\varepsilon_{L}^{L}\right) M^{*}+\frac{w_{M}}{c}\right),
$$

where $M^{*}+\frac{w_{M}}{C}=\frac{\gamma w_{L}}{c}$ and

$$
\eta_{H}^{f}=\varepsilon_{H}^{L}\left(1+\gamma \frac{M^{*}}{L^{*}}\right)
$$

For instance, Görg and Hanley (2005) have used plant-level data of the Irish electronic sector to empirically conclude that international outsourcing reduces plant-level labor demand. 
The higher is outsourcing due to various parameter changes, we then have the following effects

$$
\begin{aligned}
& \frac{\partial \eta_{L}^{f}}{\partial M^{*}}=\left(1+\varepsilon_{L}^{L}\right) \gamma\left[\frac{L^{*}-M^{*} L_{M}^{*}}{L^{* 2}}\right]-\frac{\gamma w_{M} L_{M}^{*}}{c L^{* 2}}=\frac{\gamma}{L^{*}}\left(\left(1+\varepsilon_{L}^{L}\right)\left(1+\gamma \frac{M^{*}}{L^{*}}\right)+\frac{\gamma w_{M}}{c L^{*}}\right)>0 \text { and } \\
& \frac{\partial \eta_{H}^{f}}{\partial M^{*}}=\varepsilon_{H}^{L} \gamma\left[\frac{L^{*}-M^{*} L_{M}^{*}}{L^{* 2}}\right]=\varepsilon_{H}^{L} \frac{\gamma}{L^{*}}\left(1+\gamma \frac{M^{*}}{L^{*}}\right)>0 \text {. These are in conformity with }
\end{aligned}
$$
empirical evidence according to which higher outsourcing increases the wage elasticities of low-skilled labor demand. ${ }^{5}$ Also one can show that higher outsourcing productivity will increase the wage elasticities, and even more concerning the own wage elasticity in the presence of flexible outsourcing, i.e. $\frac{\partial \eta_{L}^{f}}{\partial \gamma}>0$.

The higher outsourcing cost and outsourcing wage will decrease the own wage elasticity of low-skilled labor

$$
\frac{\partial \eta_{L}^{f}}{\partial c}=\left(1+\varepsilon_{L}^{L}\right) \gamma\left[\frac{L^{*} M_{c}^{*}-M^{*} L_{c}^{*}}{L^{* 2}}\right]-\frac{\gamma W_{M}}{c^{2}}\left[\frac{L^{*}+c L_{c}^{*}}{L^{* 2}}\right]<0
$$

and

$$
\frac{\partial \eta_{L}^{f}}{\partial w_{M}}=\left(1+\varepsilon_{L}^{L}\right) \gamma\left[\frac{L^{*} M_{w_{M}}^{*}-M^{*} L_{w_{M}}^{*}}{L^{* 2}}\right]+\frac{\gamma}{c}\left[\frac{L^{*}-w_{M} L_{w_{M}}^{*}}{L^{* 2}}\right]<0,
$$

and it will also have the same qualitative effects on the cross wage elasticity of lowskilled labor, i.e.

$$
\frac{\partial \eta_{H}^{f}}{\partial c}=\varepsilon_{H}^{L} \gamma\left[\frac{L^{*} M_{c}^{*}-M^{*} L_{c}^{*}}{L^{* 2}}\right]=\frac{\varepsilon_{H}^{L} \gamma M^{*}}{c L^{*}}\left[\frac{M_{c}^{*} c}{M^{*}}-\frac{L_{c}^{*} c}{L^{*}}\right]=-\frac{\varepsilon_{H}^{L} \gamma M^{*}}{w_{M} L^{*}}\left(1+\gamma \frac{M^{*}}{L^{*}}\right),
$$

$5 \quad$ Slaughter (2001) and Hasan et al. (2007) have shown in empirics that international trade has increased the wage elasticity of labor demand. 


$$
\begin{aligned}
& \frac{\partial \eta_{H}^{f}}{\partial w_{M}}=\varepsilon_{H}^{L} \gamma\left[\frac{L^{*} M_{w_{M}}^{*}-M^{*} L_{w_{M}}^{*}}{L^{* 2}}\right]=\frac{\varepsilon_{H}^{L} \gamma M^{*}}{w_{M} L^{*}}\left[\frac{M_{w_{M}}^{*} w_{M}}{M^{*}}-\frac{L_{w_{M}}^{*} w_{M}}{L^{*}}\right]= \\
& -\frac{\varepsilon_{H}^{L} \gamma M^{*}}{w_{M} L^{*}}\left(1+\gamma \frac{M^{*}}{L^{*}}\right) \frac{w_{M}}{c M^{*}}=-\frac{\varepsilon_{H}^{L} \gamma}{c L^{*}}\left(1+\gamma \frac{M^{*}}{L^{*}}\right)<0
\end{aligned}
$$

Finally, substituting the RHS of equation (5) into the relationship between $H$ and $L+\gamma M$ in equation (3) by using the production function $F(H, L, M)=\left[H^{a}(L+\gamma M)^{1-a}\right]^{\rho}$ gives the following demand for the skilled labor

$$
H^{*}=\frac{m a}{1-a} w_{H}^{-\varepsilon_{H}^{H}} w_{L}^{-\varepsilon_{L}^{H}}
$$

where $\varepsilon_{H}^{H}=-\frac{H_{w_{H}}^{*} w_{H}}{H^{*}}=\frac{1-\rho(1-a)}{1-\rho}>1$, and $\varepsilon_{L}^{H}=-\frac{H_{w_{L}}^{*} w_{L}}{H^{*}}=\frac{\rho(1-a)}{1-\rho}>0$. These elasticities are also higher with weaker decreasing returns to scale, but unlike in the case with the low-skilled labor, both the own wage and cross wage labor demand elasticities are independent of outsourcing. The higher own wage, and cross wage will of course affect negatively the high-skilled labor demand.

We can now summarize our findings regarding the properties of the domestic labor demand in the presence of flexible outsourcing as follows.

Proposition 1 In the presence of flexible outsourcing

(a) the own wage elasticity and the cross wage elasticity for the lowskilled labor demand depend negatively on the outsourcing wage and outsourcing cost, whereas

(b) both the own wage and the cross wage elasticities for the high-skilled labor demand are directly independent of the outsourcing wage and outsourcing . 


\subsection{Wage Formation for High-Skilled Workers}

\subsubsection{Optimal Labor Supply of High-Skilled Workers}

We assume for simplicity that the market equilibrium for the high-skilled wage $w_{H}$ follows from the equality of labor demand and labor supply in the case of CES utility function. First we derive labor supply and after that wage formation from market equilibrium by taking the low-skilled wage $w_{L}$ as given.

We assume that the government can employ the proportional wage tax $t_{H}$ for skilled worker, which is levied on the wage rate $w_{H}$ minus tax exemption $e_{H}$. Thus the total tax base in this case is $\left(w_{H}-e_{H}\right) H$, where $H$ is labour supply. In the presence of positive tax exemption the marginal wage tax exceeds the average wage tax rate $t_{H}\left(1-e_{H} / w_{H}\right)$ so that the system is linearly progressive. ${ }^{6}$ The net-of-tax wage, the skilled worker receives, is $\hat{w}_{H}=\left(1-t_{H}\right) w_{H}+t_{H} e_{H}$.

We assume that labor supply of the high-skilled worker $H$ is determined by utility maximization s.t. $\hat{w}_{H} H=C$. Using the static CES utility function in terms of consumption $C$ and leisure $1-H$ the labor supply by the high-skilled worker is determined by maximizing

$$
u(C, H)=\left[\alpha(C)^{\frac{\delta-1}{\delta}}+(1-\alpha)(1-H)^{\frac{\delta-1}{\delta}}\right]^{\frac{\delta}{\delta-1}} \text { s.t. } \hat{w}_{H} H=C
$$

where $0<\alpha<1$, and $\delta$ describes the elasticity of substitution between consumption and leisure. By using the notation $Z=\alpha\left(\hat{w}_{H} H\right)^{\frac{\delta-1}{\delta}}+(1-\alpha)(1-H)^{\frac{\delta-1}{\delta}}$ the first-order condition for labor supply can be expressed as follows

For a seminal paper about tax progression, see Musgrave and Thin (1948), and for another elaboration, see e.g. Lambert (2001, chapters 7-8). 


$$
u_{H}(C, H)=Z^{\frac{1}{\delta-1}}\left[\alpha\left(\hat{w}_{H} H\right)^{-\frac{1}{\delta}} \hat{w}_{H}-(1-\alpha)(1-H)^{-\frac{1}{\delta}}\right]=0
$$

so that we have the following labor supply

$$
H^{s}=\frac{(1-\alpha)^{-\delta}}{(1-\alpha)^{-\delta}+\alpha^{-\delta}\left(\hat{w}_{H}\right)^{1-\delta}}=\frac{1}{\left[1+\left(\frac{1-\alpha}{\alpha}\right)^{\delta}\left(\hat{w}_{H}\right)^{1-\delta}\right]}
$$

The effects of the wage $w_{H}$, wage tax $0<t_{H}<1$ and tax exemption $e_{H} \geq 0$ on the optimal labor supply are in this case the following

$$
\begin{aligned}
& \frac{\partial H^{s}}{\partial w_{H}}=-\frac{\left(\frac{1-\alpha}{\alpha}\right)^{\delta}(1-\delta)\left(\hat{w}_{H}\right)^{-\delta}\left(1-t_{H}\right)}{\left[1+\left(\frac{1-\alpha}{\alpha}\right)^{\delta}\left(\hat{w}_{H}\right)^{1-\delta}\right]^{2}}\{=\} \quad \text { as } \quad \delta\{=\} 1, \\
& \frac{\partial H^{s}}{\partial t_{H}}=\frac{\left(\frac{1-\alpha}{\alpha}\right)^{\delta}(1-\delta)\left(\hat{w}_{H}\right)^{-\delta}\left(w_{H}-e_{H}\right)}{\left[1+\left(\frac{1-\alpha}{\alpha}\right)^{\delta}\left(\hat{w}_{H}\right)^{1-\delta}\right]^{2}}\left\{\begin{array}{l}
< \\
>
\end{array}=\right\} \text { as } \delta\left\{\begin{array}{l}
> \\
>
\end{array}\right\} 1, \\
& \frac{\partial H^{s}}{\partial e_{H}}=-\frac{\left(\frac{1-\alpha}{\alpha}\right)^{\delta}(1-\delta)\left(\hat{w}_{H}\right)^{-\delta} t_{H}}{\left[1+\left(\frac{1-\alpha}{\alpha}\right)^{\delta}\left(\hat{w}_{H}\right)^{1-\delta}\right]^{2}}\left\{\begin{array}{l}
> \\
<
\end{array}=\left\{\begin{array}{l}
\text { as } \quad \delta\{=\} \\
<
\end{array}=\right\}\right.
\end{aligned}
$$

Therefore higher wage rate and tax exemption will increase (decrease) labor supply of high-skilled worker if the elasticity of substitution $\delta$ between consumption $C$ and leisure $1-H$ is higher (smaller) than one, while higher wage tax will decrease (increase) labor supply of high-skilled worker if the elasticity of substitution $\delta$ between consumption $C$ and leisure $1-H$ is higher (smaller) than one. In the case of Cobb-Douglas (C-D) utility function with $\delta=1$ labor supply does not depend on 
wage rate, $w_{H}$, wage tax $t_{H}$ and tax exemption $e$ because $\left.H^{s}\right|_{\delta=1}=\frac{1}{\left[1+\left(\frac{1-\alpha}{\alpha}\right)\right]}=\alpha$

\subsubsection{Market Equilibrium and Comparative Statics for High-Skilled Wage Formation}

Unlike in the case of low-skilled workers we assume that the high-skilled wage $w_{H}$ is determined by the market equilibrium concerning the equality of the labor demand function and the labor supply function. Now equality of demand, equation (8), and supply of labor, equation (11), $H^{*}=H^{s}$ gives

$$
\frac{m a}{1-a} w_{H}^{-\varepsilon_{H}^{H}} w_{L}^{-\varepsilon_{L}^{H}}=\frac{1}{\left[1+\left(\frac{1-\alpha}{\alpha}\right)^{\delta}\left(\hat{w}_{H}\right)^{1-\delta}\right]}
$$

which can be expressed implicitly in terms of high-skilled and low-skilled wages as

$$
w_{H}^{-\varepsilon_{H}^{H}}+\left(\frac{1-\alpha}{\alpha}\right)^{\delta} w_{H}^{-\varepsilon_{H}^{H}} \hat{w}_{H}^{1-\delta}=\frac{(1-a)}{m a} w_{L}^{\varepsilon_{L}^{H}}
$$

In the case of C-D utility function under $\delta=1$ equation (14) can be written explicitly as

$w_{H}=\left[\frac{(1-a) \alpha}{m a}\right]^{-\frac{1}{\varepsilon_{H}^{H}}} w_{L}^{-\frac{\varepsilon_{L}^{H}}{\varepsilon_{H}^{H}}}$. The relationship from the implicit function (14) between the changes in the high-skilled wage $w_{H}$ and the low-skilled wage $w_{L}$ is the following

one $\left[-\varepsilon_{H}^{H} w_{H}^{-\varepsilon_{H}^{H}-1}+\left(\frac{1-\alpha}{\alpha}\right)^{\delta}\left(-\varepsilon_{H}^{H} w_{H}^{-\varepsilon_{H}^{H}-1} \hat{w}_{H}^{1-\delta}+(1-\delta) w_{H}^{-\varepsilon_{H}^{H}} \hat{w}_{H}^{-\delta}\left(1-t_{H}\right)\right)\right] d w_{H}=\varepsilon_{L}^{H} \frac{(1-a)}{m a} w_{L}^{\varepsilon_{L}^{H}-1} d w_{L}$

where 


$$
\begin{aligned}
& {\left[-\varepsilon_{H}^{H} w_{H}^{-\varepsilon_{H}^{H}-1}+\left(\frac{1-\alpha}{\alpha}\right)^{\delta}\left(-\varepsilon_{H}^{H} w_{H}^{-\varepsilon_{H}^{H}-1} \hat{w}_{H}^{1-\delta}+(1-\delta) w_{H}^{-\varepsilon_{H}^{H}} \hat{w}_{H}^{-\delta}\left(1-t_{H}\right)\right)\right]=-\varepsilon_{H}^{H} w_{H}^{-\varepsilon_{H}^{H}-1}+} \\
& \left.\left(\frac{1-\alpha}{\alpha}\right)^{\delta}\left[\left(1-t_{H}\right)\left(1-\delta-\varepsilon_{H}^{H}\right)-\varepsilon_{H}^{H} t_{H} e w_{H}^{-1}\right)\right] w_{H}^{-\varepsilon_{H}^{H}} \hat{w}_{H}^{-\delta}<0
\end{aligned}
$$

because $1-\varepsilon_{H}^{H}=-\varepsilon_{H}^{L}=-\frac{\rho a}{1-\rho}<0$ so that $1-\varepsilon_{H}^{H}-\delta<0$. This can now be expressed as

$$
\left.\frac{d w_{H}}{d w_{L}}\right|_{\delta \neq 1}=\frac{\varepsilon_{L}^{H} \frac{(1-a)}{m a} w_{L}^{\varepsilon_{L}^{H}-1}}{\left(-\varepsilon_{H}^{H} w_{H}^{-\varepsilon_{H}^{H}-1}+\left(\frac{1-\alpha}{\alpha}\right)^{\delta}\left[\left(1-t_{H}\right)\left(1-\varepsilon_{H}^{H}-\delta\right)-\varepsilon_{H}^{H} t_{H} e_{H} w_{H}^{-1}\right] w_{H}^{-\varepsilon_{H}^{H}} \hat{w}_{H}^{-\delta}\right)}<0 .
$$

In this more general CES utility function case there is a negative relationship between the high-skilled wage and the low-skilled wage, which comes via the highskilled labor demand, where the los-skilled wage have a negative effect on the highskilled labor demand due to complementary of $H$ and $L$ in terms of production. This implies that higher outsourcing concerning domestic labor input will increase the wage rate of high-skilled workers because it decreases the wage rate of lowskilled-workers, which lies in conformity with empirics. It has been empirically shown that higher outsourcing will decrease wage formation of low-skilled workers and increase wage formation of high-skilled workers, i.e. that wage dispersion will increase. $^{7}$

The relationship from the implicit function (14) between the changes in the high-skilled wage $w_{H}$ and tax parameters are as

See evidence from various countries which lies in conformity with this, e.g. Braun and Scheffel (2007), Feenstra and Hanson (1999, 2003), Hijzen et al (2005), Hijzen (2007), Egger and Egger (2006), Munch and Skaksen (2009), Riley and Young (2007) and Geishecker and Görg (2008). 


$$
\begin{aligned}
& \left.\frac{d w_{H}}{d t_{H}}\right|_{\delta \neq 1}=\frac{(1-\delta)\left(w_{H}-e_{H}\right)\left(\frac{(1-\alpha)}{\alpha}\right)^{\delta} w_{H}^{-\varepsilon_{H}^{H}} \hat{w}_{H}^{-\delta}}{\left(-\varepsilon_{H}^{H} w_{H}^{-\varepsilon_{H}^{H}-1}+\left(\frac{1-\alpha}{\alpha}\right)^{\delta}\left[\left(1-t_{H}\right)\left(1-\varepsilon_{H}^{H}-\delta\right)-\varepsilon_{H}^{H} t_{H} e_{H} w_{H}^{-1}\right] w_{H}^{-\varepsilon_{H}^{H}} \hat{w}_{H}^{-\delta}\right)}\{=\} 0 \text { as } \\
& \delta\left\{\begin{array}{l}
> \\
=\{1,
\end{array}\right.
\end{aligned}
$$

and

$$
\begin{aligned}
& \left.\left.\frac{d w_{H}}{d e_{H}}\right|_{\delta \neq 1}=\frac{-(1-\delta) t_{H}\left(\frac{1-\alpha}{\alpha}\right)^{\delta} w_{H}^{-\varepsilon_{H}^{H}} \hat{w}_{H}^{-\delta}}{\left(-\varepsilon_{H}^{H} w_{H}^{-\varepsilon_{H}^{H}-1}+\left(\frac{1-\alpha}{\alpha}\right)^{\alpha}\left[\left(1-t_{H}\right)\left(1-\varepsilon_{H}^{H}-\delta\right)-\varepsilon_{H}^{H} t_{H} e_{H} w_{H}^{-1}\right] w_{H}^{-\varepsilon_{H}^{H}} \hat{w}_{H}^{-\delta}\right)}\{=\} 0\right\} \text { as } \\
& \delta\left\{\begin{array}{l}
> \\
=\{1 .
\end{array}\right. \\
& <
\end{aligned}
$$

According to these calculations, higher wage tax and lower tax exemption will increase (decrease) the high-skilled wage if the elasticity of substitution $\delta$ between consumption $C$ and leisure $1-H$ is higher (smaller) than one, because under these conditions labor supply decreases (increases) (see equations (12b-c for details).

In the case of C-D utility function we have also the negative relationship between $w_{H}$ and $w_{L}$, i.e.

$$
\left.\frac{d w_{H}}{d w_{L}}\right|_{\delta=1}=-\frac{\varepsilon_{L}^{H}}{\varepsilon_{H}^{H}} \frac{w_{H}}{w_{L}}<0
$$

so that $\left.\frac{d w_{H}}{d w_{L}} \frac{w_{L}}{w_{H}}\right|_{\delta=1}=-\frac{\varepsilon_{L}^{H}}{\varepsilon_{H}^{H}}<0$. In the case of C-D utility function, there is no effect of tax parameters on the high-skilled workers. 
We can now summarize our findings regarding the properties of the highskilled wage determination in the presence of outsourcing as follows.

Proposition 2 In the presence of flexible outsourcing both in the case of high -skilled workers' CES and in the case of C-D utility function in competitive labor market equilibrium

(a) the high-skilled wage depends negatively on the low-skilled wage, whereas

(b) the high-skilled wage depends positively (negatively) on the wage tax when the elasticity of substitution between consumption and leisure is higher (lower ) than one, whereas

(c) the high-skilled wage depends negatively (positively) on the tax exemption when the elasticity of substitution between consumption and leisure is higher (lower) than one, while the high-skilled wage is independent of tax parameters under $C-D$ utility function.

\section{Wage Formation by Monopoly Labor Union for Low-Skilled Workers}

Now we analyze the wage formation of low-skilled workers so that it takes place in anticipation of optimal labor and outsourcing decisions by the firm. We analyze the wage formation by the monopoly union (see also Cahuc and Zylberberg (2004), p. 401 - 403 concerning the monopoly union specification), which determines the wage for low-skilled workers in anticipation of optimal in-house low-skilled labor demand in the presence of flexible outsourcing determined simultaneously and of market equilibrium for the high-skilled wage $w_{H}$. It might also be important to analyze wage formation of low-skilled workers in terms of decentralized wage setting in the presence of flexible outsourcing.

\subsection{Wage Formation by the Monopoly Labor Union}


The market equilibrium for the high-skilled wage $w_{H}$ follows from the equality of labor demand and the labor supply by focusing the case of a CES utility function, presented in Section III. The monopoly labor union determines the wage for low-skilled workers in anticipation of optimal domestic labor demands and highskilled wage and outsourcing decisions by the firm. We assume that government can employ a proportional tax rate $t_{L}$, which is levied on the wage rate $w_{L}$ minus a tax exemption $e_{L}$, i.e. the total tax base is $\left(w_{L}-e_{L}\right) L^{*}$. In the presence of a positive tax exemption the marginal wage tax exceeds the average wage tax rate $t_{L}\left(1-e_{L} / w_{L}\right)$ so that the system is linearly progressive and the net-of-tax wage is $\hat{w}_{L}=\left(1-t_{L}\right) w_{L}+t_{L} e_{L}$. The labour tax systems in all the OECD countries are progressive and show significant differences in the degree of tax progression. ${ }^{8}$

The objective function of the labour union is assumed to be $V=\left(\left(1-t_{L}\right) w_{L}+t_{L} e_{L}-b_{L}\right) L^{*}+b_{L} N=\left(\hat{w}_{L}-b_{L}\right) L^{*}+b_{L} N$, where $b_{L}$ is the (exogenous) outside option available to the unskilled workers and $N$ is the number of labor union members. The monopoly labour union sets wage for the unskilled workers so as to maximize the surplus according to

$$
\begin{aligned}
& \underbrace{\max }_{\left(w_{L}\right)} V=\left(\hat{w}_{L}-b_{L}\right) L^{*}+b_{L} N \\
& \text { s.t. } L^{*}=m w_{L}^{-\varepsilon_{L}^{L}} w_{H}^{-\varepsilon_{H}^{L}}-\gamma M^{*}=m w_{L}^{-\varepsilon_{L}^{L}} w_{H}^{-\varepsilon_{H}^{L}}-\gamma\left(\frac{\gamma w_{L}-w_{M}}{c}\right) \text { and } H^{*}=H^{s}
\end{aligned}
$$

where the high-skilled labor demand is $H^{*}=\frac{m a}{1-a} w_{H}^{-\varepsilon_{H}^{H}} w_{L}^{-\varepsilon_{L}^{H}}$ and the high-skilled labor supply is $H^{s}=\frac{1}{\left[1+\left(\frac{1-\alpha}{\alpha}\right)^{\delta}\left(w_{H}\right)^{1-\delta}\right]}$, so that $\quad H^{*}=H^{s} \quad$ implies 
$w_{H}^{-\varepsilon_{H}^{H}}+\left(\frac{1-\alpha}{\alpha}\right)^{\delta} w_{H}^{-\varepsilon_{H}^{H}} \hat{w}_{H}^{1-\delta}=\frac{(1-a)}{m a} w_{L}^{\varepsilon_{L}^{H}}$ (see equations (8), (11) and (14)). The firstorder condition associated with (17) can be written as (see Appendix A)

$$
\left.V_{w_{L}}=\left(1-t_{L}\right) w_{L}\left(1-\left(\eta_{L}^{f}+\eta_{H}^{f} \frac{d w_{H}}{d w_{L}} \frac{w_{L}}{w_{H}}\right)\right)+\left(b_{L}-t_{L} e_{L}\right)\left(\eta_{L}^{f}+\eta_{H}^{f} \frac{d w_{H}}{d w_{L}} \frac{w_{L}}{w_{H}}\right)\right)=0
$$

where in the case of CES-utility function $\left.\frac{d w_{H}}{d w_{L}} \frac{w_{L}}{w_{H}}\right|_{\delta \neq 1}=\frac{\varepsilon_{L}^{H} \frac{(1-a)}{m a} w_{L}^{\varepsilon_{L}^{H}}}{\left[-\varepsilon_{H}^{H} w_{H}^{-\varepsilon_{H}^{H}}+\left(\frac{1-\alpha}{\alpha}\right)^{\delta}\left[w_{H}\left(1-t_{H}\right)\left(1-\varepsilon_{H}^{H}-\delta\right)-\varepsilon_{H}^{H} t_{H} e_{H}\right] w_{H}^{-\varepsilon_{H}^{H}} \hat{w}_{H}^{-\delta}\right]}<0$ and and in the case of C-D utility function $\left.\frac{d w_{H}}{d w_{L}} \frac{w_{L}}{w_{H}}\right|_{\delta=1}=-\frac{\varepsilon_{L}^{H}}{\varepsilon_{H}^{H}}<0$. Using the equation (14) these can be re-expressed as follows

$$
\left.\frac{d w_{H}}{d w_{L}} \frac{w_{L}}{w_{H}}\right|_{\delta \neq 1}=-\frac{\varepsilon_{L}^{H}}{\varepsilon_{H}^{H}} \frac{\left[1+\left(\frac{1-\alpha}{\alpha}\right)^{\delta} \hat{w}_{H}^{1-\delta}\right]}{\left[1+\left(\frac{1-\alpha}{\alpha}\right)^{\delta} \hat{w}_{H}^{1-\delta}-\left(\frac{1-\alpha}{\alpha}\right)^{\delta} w_{H}\left(1-t_{H}\right)(1-\delta) \hat{w}_{H}^{-\delta}\right]}=-\frac{\varepsilon_{L}^{H}}{\varepsilon_{H}^{H}} \frac{T}{U}<0
$$

and $\left.\frac{d w_{H}}{d w_{L}} \frac{w_{L}}{w_{H}}\right|_{\delta=1}=-\frac{\varepsilon_{L}^{H}}{\varepsilon_{H}^{H}}<0$

where $\quad T=1+\left(\frac{1-\alpha}{\alpha}\right)^{\delta} \hat{w}_{H}^{1-\delta}>0$ and $\quad U=1+\left(\frac{1-\alpha}{\alpha}\right)^{\delta} \hat{w}_{H}^{-\delta}\left(t_{H} e_{H}+w_{H}\left(1-t_{H}\right) \delta\right)>0$. Using (19a-b) in equation (18) can be presented implicitly as follows in the case of CES and C-D utility functions (see Appendix A) 


$$
\left.w_{L}^{*}\right|_{\delta \neq 1}=\left(\frac{\eta_{L}^{f}+\eta_{H}^{f} \frac{d w_{H} w_{L}}{d w_{L} w_{H}}}{\eta_{L}^{f}+\eta_{H}^{f} \frac{d w_{H} w_{L}}{d w_{L} w_{H}}-1}\right) \hat{b}=\left(\frac{\eta_{L}^{f}-\eta_{H}^{f} \frac{\varepsilon_{L}^{H}}{\varepsilon_{H}^{H}} \frac{T}{U}}{\eta_{L}^{f}-\eta_{H}^{f} \frac{\varepsilon_{L}^{H}}{\varepsilon_{H}^{H}} \frac{T}{U}-1}\right) \hat{b}
$$

and

$$
\left.w_{L}^{*}\right|_{\delta=1}=\left(\frac{\eta_{L}^{f}-\eta_{H}^{f} \frac{\varepsilon_{L}^{H}}{\varepsilon_{H}^{H}}}{\eta_{L}^{f}-\eta_{H}^{f} \frac{\varepsilon_{L}^{H}}{\varepsilon_{H}^{H}}-1}\right) \hat{b}
$$

where $\hat{b}_{L}=\frac{b_{L}-t_{L} e_{L}}{1-t_{L}}$. The own wage and cross wage elasticities of low-skilled labor demand $\quad$ are $\left.\quad \eta_{L}^{f}=\varepsilon_{L}^{L}\left(1+\gamma \frac{M^{*}}{L^{*}}\right)+\gamma \frac{M^{*}}{L^{*}}+\gamma \frac{w_{M}}{c L^{*}}\right) \quad$ and $\quad \eta_{H}^{f}=\varepsilon_{H}^{L}\left(1+\gamma \frac{M^{*}}{L^{*}}\right) \quad$ (see equations (6a-6b). These low-skilled labor demand elasticities are not constant because the low-skilled labor demand, $L^{*}=m w_{L}^{-\varepsilon_{L}^{L}} w_{H}^{-\varepsilon_{H}^{L}}-\gamma M^{*}=m w_{L}^{-\varepsilon_{L}^{L}} w_{H}^{-\varepsilon_{H}^{L}}-\gamma\left(\frac{\gamma w_{L}-w_{M}}{c}\right)$ depends negatively in the nonlinear way on the following variables: the high-skilled wage, the low-skilled wage, outsourcing wage and outsourcing cost and the productivity of the outsourced labor input relative to the domestic low-skilled labor input.

The optimal low-skilled wage (20a-b) also the case of the monopoly labor union is an implicit form in the presence of outsourcing, because the mark-up $A^{f}=\left(\frac{\eta_{L}^{f}-\eta_{H}^{f} \frac{\varepsilon_{L}^{H}}{\varepsilon_{H}^{H}} \frac{T}{U}}{\eta_{L}^{f}-\eta_{H}^{f} \frac{\varepsilon_{L}^{H}}{\varepsilon_{H}^{H}} \frac{T}{U}-1}\right)$ depends on the low-skilled wage rate in a non-linear way so that it cannot be solved explicitly for the optimal domestic low-skilled wage. Equations (20a-b)) can be expressed as

$$
\left.w_{L}^{*}\right|_{\delta \neq 1}=\left(\frac{\bar{\eta}_{L}^{f}}{\bar{\eta}_{L}^{f}-1}\right) \hat{b}_{L}=\left(\frac{\left(\varepsilon_{L}^{L}-\frac{\varepsilon_{H}^{L} \varepsilon_{L}^{H}}{\varepsilon_{H}^{H}} \frac{T}{U}\right)\left(L^{*}+\gamma M^{*}\right)+\gamma\left(M^{*}+\frac{w_{M}}{c}\right)}{\left(\varepsilon_{L}^{L}-\frac{\varepsilon_{H}^{L} \varepsilon_{L}^{H}}{\varepsilon_{H}^{H}} \frac{T}{U}\right)\left(L^{*}+\gamma M^{*}\right)+\gamma\left(M^{*}+\frac{w_{M}}{c}\right)-1}\right) \hat{b}_{L}
$$




$$
\left.w_{L}^{*}\right|_{\delta=1}=\left(\frac{\bar{\eta}_{L}^{f}}{\bar{\eta}_{L}^{f}-1}\right) \hat{b}_{L}=\left(\frac{\bar{\varepsilon}\left(L^{*}+\gamma M^{*}\right)+\gamma\left(M^{*}+\frac{w_{M}}{c}\right)}{\bar{\varepsilon}\left(L^{*}+\gamma M^{*}\right)+\gamma\left(M^{*}+\frac{w_{M}}{c}\right)-1}\right) \hat{b}_{L},
$$

where where $\bar{\eta}_{L}^{f}=\left(\varepsilon_{L}^{L}-\frac{\varepsilon_{H}^{L} \varepsilon_{L}^{H}}{\varepsilon_{H}^{H}} \frac{T}{U}\right)\left(1+\gamma \frac{M^{*}}{L^{*}}\right)+\frac{\gamma}{L^{*}}\left(M^{*}+\frac{w_{M}}{C}\right)$ and in the presence of C-D utility function of high-skilled workers we have the following implicit form for lowskilled wage $\left.\bar{\eta}_{L}^{f}\right|_{\delta=1}=\bar{\varepsilon}\left(1+\gamma \frac{M^{*}}{L^{*}}\right)+\frac{\gamma}{L^{*}}\left(M^{*}+\frac{w_{M}}{c}\right)$ and $\bar{\varepsilon}=\frac{1}{1-\rho(1-a)}>1$.

\subsection{Comparative Statics of Low-Skilled Wage Formation}

In order to characterize the effect of parameters on the unskilled monopoly trade wage formation it is applied the implicit differentiation. In terms of comparative statics of the outside option for unemployment benefit we have from the implicit wage formation (21a) the following result

$$
\left(1-\frac{\left[\left(\bar{\eta}_{L}^{f}-1\right) \frac{\partial \bar{\eta}_{L}^{f}}{\partial w_{L}}-\bar{\eta}_{L}^{f} \frac{\partial \bar{\eta}_{L}^{f}}{\partial w_{L}}\right]}{\left(\bar{\eta}_{L}^{f}-1\right)^{2}} \hat{b}_{L}\right) d w_{L}^{*}=\left(\frac{\bar{\eta}_{L}^{f}}{\left.\bar{\eta}_{L}^{f}-1\right)}\right) d \hat{b}_{L}
$$

so that by using $\hat{b}_{L}=w_{L}^{*}\left(\bar{\eta}_{f}-1\right) / \bar{\eta}_{f}$ this can be expressed as

$$
\frac{d w_{L}^{*}}{d \hat{b}_{L}}=\left(\frac{\bar{\eta}_{L}^{f}}{\bar{\eta}_{L}^{f}-1+\frac{\partial \bar{\eta}_{L}^{f}}{\partial w_{L}} \frac{w_{L}}{\bar{\eta}_{L}^{f}}}\right)>0
$$

where $\bar{\eta}_{f}>1$ and $\frac{\partial \bar{\eta}_{L}^{f}}{\partial w_{L}}>0$. According to (23) the effect of outside option on lowskilled wage formation is qualitatively the same with and without outsourcing because the mark-up in the presence of CES utility function is 
$\left.A\right|_{M=0, \delta \neq 1}=\left(\frac{\left(\varepsilon_{L}^{L}-\frac{\varepsilon_{H}^{L} \varepsilon_{L}^{H}}{\varepsilon_{H}^{H}} \frac{T}{U}\right)}{\left(\varepsilon_{L}^{L}-\frac{\varepsilon_{H}^{L} \varepsilon_{L}^{H}}{\varepsilon_{H}^{H}} \frac{T}{U}\right)-1}\right)$ so that $\left.\frac{d w_{L}^{*}}{d \hat{b}_{L}}\right|_{M=0, \delta \neq 1}=\left.A\right|_{M=0}>0$. In the presence of

C-D utility function without outsourcing the mark-up is $A_{M=0, \delta=1}=\left(\frac{\bar{\varepsilon}}{\bar{\varepsilon}-1}\right)$ so that $\left.\frac{d w_{L}^{*}}{d \hat{b}_{L}}\right|_{M=0, \delta=1}=\left.A\right|_{M=0, \delta=1}>0 .^{9}$

Differentiating the implicit wage formation (21a) with respect to the lowskilled wage and the outsourcing wage gives

$$
\left(1-\frac{\left[\left(\bar{\eta}_{L}^{f}-1\right) \frac{\partial \bar{\eta}_{L}^{f}}{\partial w_{L}}-\bar{\eta}_{L}^{f} \frac{\partial \bar{\eta}_{L}^{f}}{\partial w_{L}}\right]}{\left(\bar{\eta}_{L}^{f}-1\right)^{2}} \hat{b}_{L}\right) d w_{L}^{*}=\frac{\left[\left[\left(\bar{\eta}_{L}^{f}-1\right) \frac{\partial \bar{\eta}_{L}^{f}}{\partial w_{H}}-\bar{\eta}_{L}^{f} \frac{\partial \bar{\eta}_{L}^{f}}{\partial w_{H}}\right]\right]}{\left(\bar{\eta}_{L}^{f}-1\right)^{2}} \hat{b}_{L} d w_{H}
$$

which can be expressed by using $\hat{b}_{L}=w_{L}^{*}\left(\bar{\eta}_{f}-1\right) / \bar{\eta}_{f}$ as follows

$$
\frac{d w_{L}^{*}}{d w_{M}}=-\left(\frac{\frac{\partial \bar{\eta}_{L}^{f}}{\partial w_{H}} \frac{w_{L}}{\bar{\eta}_{L}^{f}}}{\bar{\eta}_{L}^{f}-1+\frac{\partial \bar{\eta}_{L}^{f}}{\partial w_{L}} \frac{w_{L}}{\bar{\eta}_{L}^{f}}}\right)>0
$$

where

9 Of course, in the absence of outsourcing the mark-up between outside option and wage formation $\left.A\right|_{M=0}>\left.A\right|_{M>0}>1$ is higher than in the presence of outsourcing. 


$$
\begin{aligned}
& \frac{\partial \bar{\eta}_{L}^{f}}{\partial w_{M}}=\left(1+\varepsilon_{L}^{L}-\frac{\varepsilon_{H}^{L} \varepsilon_{L}^{H}}{\varepsilon_{H}^{H}} \frac{T}{U}\right) \gamma\left[\frac{L^{*} M_{w_{H}}^{*}-M^{*} L_{w_{H}}^{*}}{L^{* 2}}\right]+\frac{\gamma}{c}\left[\frac{L^{*}-w_{M} L_{w_{H}}^{*}}{L^{* 2}}\right]= \\
& \frac{\left(1+\varepsilon_{L}^{L}-\frac{\varepsilon_{H}^{L} \varepsilon_{L}^{H}}{\varepsilon_{H}^{H}} \frac{T}{U}\right) \gamma M^{*}}{w_{H} L^{*}}\left[\frac{M_{w_{H}}^{*} w_{H}}{M^{*}}-\frac{L_{w_{H}}^{*} w_{H}}{L^{*}}\right]+\frac{\gamma}{c L^{*}}\left[1-\frac{L_{w_{H}}^{*} w_{H}}{L^{*}}\right]= \\
& -\frac{\left(1+\varepsilon_{L}^{L}-\frac{\varepsilon_{H}^{L} \varepsilon_{L}^{H}}{\varepsilon_{H}^{H}} \frac{T}{U}\right) \gamma M^{*}}{w_{H} L^{*}}\left[\frac{1}{c M^{*}}\left(1+\gamma \frac{M^{*}}{L^{*}}\right)+\frac{\gamma}{c L^{*}}\left(1-\frac{\gamma w_{M}}{L^{*}}\right)\right]<0
\end{aligned}
$$

and $\frac{\partial \bar{\eta}_{L}^{f}}{\partial w_{L}}>0$. These qualitative results are similar in the case of CD-utility function when $\left(1+\varepsilon_{L}^{L}-\frac{\varepsilon_{H}^{L} \varepsilon_{L}^{H}}{\varepsilon_{H}^{H}} \frac{T}{U}\right)=1+\bar{\varepsilon}$.

Also the effects of higher outsourcing cost are qualitatively similar, i,e. $\frac{d w_{L}^{*}}{d c}=-\left(\frac{\frac{\partial \bar{\eta}_{L}^{f}}{\partial c} \frac{w_{L}}{\bar{\eta}_{L}^{f}}}{\bar{\eta}_{L}^{f}-1+\frac{\partial \bar{\eta}_{L}^{f}}{\partial w_{L}} \frac{w_{L}}{\bar{\eta}_{L}^{f}}}\right)>0$ as $\frac{\partial \bar{\eta}_{L}^{f}}{\partial c}<0$ (equation (7a)) and equation (15a) implies $\frac{d w_{H}^{*}}{d c}<0$

In terms of comparative statics of the unskilled wage tax and the tax exemption we have the following results

$$
\begin{aligned}
\frac{d w_{L}^{*}}{d t_{L}} & =\left(\frac{\bar{\eta}_{L}^{f}}{\bar{\eta}_{L}^{f}-1+\frac{\partial \bar{\eta}_{L}^{f}}{\partial w_{L}} \frac{w_{L}}{\bar{\eta}_{L}^{f}}}\right) \frac{b_{L}-e_{L}}{\left(1-t_{L}\right)^{2}}>0 \text { as } b_{L}-e>0 \\
\frac{d w_{L}^{*}}{d e_{L}} & =-\left(\frac{\bar{\eta}_{L}^{f}}{\bar{\eta}_{L}^{f}-1+\frac{\partial \bar{\eta}_{L}^{f}}{\partial w_{L}} \frac{w_{L}}{\bar{\eta}_{L}^{f}}}\right) \frac{t_{L}}{\left(1-t_{L}\right)}<0
\end{aligned}
$$


According to (27a-27b) the effects of wage tax and tax exemption on low-skilled wage formation are qualitatively the same with and without outsourcing because $\left.\frac{d w_{L}^{*}}{d t_{L}}\right|_{M=0}=\frac{\bar{\varepsilon}}{(\bar{\varepsilon}-1)} \frac{b_{L}-e_{L}}{\left(1-t_{L}\right)^{2}}>0$ and $\left.\frac{d w_{L}^{*}}{d e_{L}}\right|_{M=0}=-\frac{\bar{\varepsilon}}{(\bar{\varepsilon}-1)} \frac{t_{L}}{\left(1-t_{L}\right)}<0$. This is because these parameters do not affect the mark-up of wage formation, but have an effect only via the outside option $\hat{b}_{L}$. Of course, in the absence of outsourcing the mark-up between outside option and wage formation $\left.A\right|_{M=0}=\frac{\bar{\varepsilon}}{\bar{\varepsilon}-1}=\frac{1}{\rho(1-a)}>1$ is higher than in the presence of outsourcing. Moreover, the equations (27a-27b) imply jointly with equations (15a-16) that $\frac{d w_{H}}{d t_{L}}<0$, and $\frac{d w_{H}}{d e}>0$ so that the higher wage tax and the higher outside option of unskilled workers will decrease the wage for the skilled labour, while the higher tax exemption of low-skilled workers will increase the wage for the skilled labour.

We can now summarize our findings in terms of the low-skilled wage formation in the presence of flexible outsourcing as follows.

Proposition 3 In the presence of flexible outsourcing both in the case of high- skilled workers' CES and C-D utility function in competitive labor market equilibrium

(a) the higher outside option will increase the wage for the low-skilled labor and therefore decrease the wage for the high-skilled labor and these qualitative results are also qualitatively similar but higher in the absence of outsourcing, and

(b) the higher outsourcing wage and the higher outsourcing cost will increase the wage for the low-skilled labor because the wage elasticity of the low-skilled labor will decrease and these will decrease the wage for the high-skilled labor. 


\section{Effects of Labor Tax Policy Under Imperfectly and Perfective Competitive Domestic Labor Markets}

Next it is analyzed the effect of labor wage tax progression on wage formation and employment by the low-skilled workers and the high-skilled workers in domestic labor.

\subsection{Effects of low-skilled wage tax progression on wage and employment}

We assume that the tax reform will keep the relative tax burden per lowskilled worker, $t_{L}\left(w_{L}-e_{L}\right)$, constant, which means

$$
t_{L}-\frac{t_{L} e_{L}}{w_{L}}=R
$$

The government can raise the degree of wage tax progression by increasing $t_{L}$ and $e_{L}$ and allowing change in $w_{L}$ under the condition $d R=0 .{ }^{10}$ Formally we have

$$
\left.\frac{d e_{L}}{d t_{L}}\right|_{d R=0,}=\frac{\left(w_{L}^{*}-e_{L}+\frac{t_{L} e_{L}}{w_{L}^{*}} \frac{\partial w_{L}^{*}}{\partial t_{L}}\right)}{\left(t_{L}-\frac{t_{L} e_{L}}{w_{L}^{*}} \frac{\partial w_{L}^{*}}{\partial e_{L}}\right)}>0 .
$$

Concerning the low-skilled wage effect of this reform we have $d w_{L}^{*}=\frac{\partial w_{L}^{*}}{\partial t_{L}} d t_{L}+\frac{\partial w_{L}^{*}}{\partial e} d e_{L}$. Dividing by $d t_{L}$ and substituting the RHS of (29) for

A way to define tax progression is to look at the average tax progression ( $A R P$ ), which is given by the difference between the marginal tax rate $t_{L}$ and the average tax rate $R$, $A R P \equiv t_{L} R$. Tax system is progressive if $A R P$ is positive and the progression is increases if the difference increases. 
$d e / d t_{L}$ gives (see Appendix B)

$$
\left.\frac{d w_{L}^{*}}{d t_{L}}\right|_{d R=0}=\frac{\left[\frac{\partial w_{L}^{*}}{\partial t_{L}}+\frac{\left(w_{L}^{*}-e_{L}\right)}{t_{L}} \frac{\partial w_{L}^{*}}{\partial e_{L}}\right]}{\left[1-\frac{e_{L}}{w_{L}^{*}} \frac{\partial w_{L}^{*}}{\partial e_{L}}\right]}<0
$$

so that a higher degree of wage tax progression, keeping the relative tax burden per low-skilled worker constant, will decrease the low-skilled wage rate. In the absence of outsourcing the qualitative effect is similar, i.e. $\left.\frac{d w_{L}^{*}}{d t_{L}}\right|_{d R=0, d M=0}<0$, but it is quantitatively different (see Appendix B).

Finally, we characterize the unskilled employment effect by raising tax progression keeping the relative tax burden per unskilled worker constant to increase $t_{L}$ and $e$ according to (29), so that we have the following employment effect $d L^{*}=\left[L_{w_{L}^{*}}^{*}+L_{w_{H}}^{*} \frac{\partial w_{H}}{\partial w_{L}^{*}}\right]\left[\frac{\partial w_{L}^{*}}{\partial t_{L}} d t_{L}+\frac{\partial w_{L}^{*}}{\partial e} d e_{L}\right]$. Dividing this by $d t_{L}$ and substituting the RHS of (29) for $d e / d t_{L}$ gives

$$
\left.\frac{d L^{*}}{d t_{L}}\right|_{d R=0}=\left.\left(L_{w_{L}^{*}}^{*}+L_{w_{H}}^{*} \frac{\partial w_{H}}{\partial w_{L}^{*}}\right) \frac{d w_{L}^{*}}{d t_{L}}\right|_{d R=0 .}=-\frac{L^{*}}{w_{L}^{*}}\left(\bar{\varepsilon}\left(1+\gamma \frac{M^{*}}{L^{*}}\right)+\gamma \frac{\gamma w_{L}}{c L^{*}}\right) \underbrace{\left.\frac{d w_{L}^{*}}{d t_{L}}\right|_{d R=0}}_{-}>0
$$

so that higher degree of wage tax progression keeping the relative tax burden per low-skilled worker constant, will increase the low-skilled labour demand. These results (30) and (31) also happen qualitatively in a similar way in the case of homogeneous domestic labour markets with outsourcing (see Koskela and Schöb (2009)). The qualitative effect is also similar in the absence of outsourcing because 
the higher degree of tax progression does not affect the mark-up of wage formation which depends on the presence and absence of outsourcing. ${ }^{11}$

The total effect concerning direct and indirect effects of changes in lowskilled wage on the skilled labour demand is zero in the case of C-D utility function of high-skilled workers, i.e. $d H^{*}=H_{w_{L}^{*}}^{*} d w_{L}^{*}+H_{w_{H}}^{*} \frac{\partial w_{H}}{\partial w_{L}^{*}} d w_{L}^{*}$ can be expressed by using equation (15a) as

$$
\left.\frac{d H^{*}}{d w_{L}^{*}}\right|_{\delta=1}=H_{w_{L}^{*}}^{*}+H_{w_{H}}^{*} \frac{d w_{H}}{d w_{L}^{*}}=\frac{H^{*}}{w_{L}^{*}}\left[\frac{H_{w_{L}^{*}}^{*} w_{L}^{*}}{H^{*}}+\frac{H_{w_{H}}^{*} w_{H}}{H^{*}} \frac{d w_{H}}{d w_{L}^{*}} \frac{w_{L}^{*}}{w_{H}}\right]=\frac{H^{*}}{w_{L}^{*}}\left[-\varepsilon_{L}^{H}-\varepsilon_{H}^{H} \frac{d w_{H}}{d w_{L}^{*}} \frac{w_{L}^{*}}{w_{H}}\right]=0
$$

In the case of CES utility function of high-skilled workers we have

$$
\begin{aligned}
\left.\frac{d H^{*}}{d w_{L}^{*}}\right|_{\delta \neq 1} & =H_{w_{L}^{*}}^{H^{*}}+H_{w_{H}}^{*} \frac{d w_{H}}{d w_{L}^{*}}=\frac{H^{*}}{w_{L}^{*}}\left[-\varepsilon_{L}^{H}-\varepsilon_{H}^{H} \frac{\varepsilon_{L}^{H}}{\varepsilon_{H}^{H}} \frac{T}{U}\right]=\underbrace{-\frac{\varepsilon_{L}^{H}}{U} \frac{H^{*}}{w_{L}^{*}}}_{-}[U-T] \\
= & \underbrace{-\frac{\varepsilon_{L}^{H}}{U} \frac{H^{*}}{w_{L}^{*}}}_{-}\left(w_{H}\left(1-t_{H}\right)+t_{H} e_{L}\right)(\delta-1)\left\{\begin{array}{l}
< \\
= \\
>
\end{array}\right\} \text { as } \quad \delta\left\{\begin{array}{l}
> \\
=\} \\
<
\end{array}\right)
\end{aligned}
$$

We can now summarize our findings in terms of the low-skilled wage formation and labour demand in the presence of flexible outsourcing as follows.

Proposition 4 In the presence of flexible outsourcing

(a) a higher degree of tax progression by raising the wage tax and the tax exemption for the low-skilled workers to keep the relative burden per low-skilled worker constant will decrease the wage rate and increase labour demand of low-skilled workers, whereas

This has been analyzed in the absence of outsourcing under imperfectly competitive homogeneous domestic labor markets e.g. in Koskela and Vilmunen (1996) and in Koskela and Schöb (2002). 
(b) it will decrease (increase) employment of high-skilled workers in CES utility function when the elasticity of substitution between consumption and leisure is higher (lower) than one, while it will have no effect on employment of high-skilled workers in the case of $C$-D utility function of high-skilled workers and

(c) qualitatively similar effects arise in the absence of outsourcing.

\subsection{Effects of high-skilled wage tax progression on wage and employment}

We assume that the tax reform will keep the relative tax burden per highskilled worker, $t_{H}\left(w_{H}-e\right)$, constant, which means

$$
t_{H}-\frac{t_{H} e_{H}}{w_{H}}=R^{H} .
$$

The government can raise the degree of wage tax progression by increasing $t_{H}$ and $e_{H}$ and allowing change in $w_{H}$ under the condition $d R^{H}=0$. Formally we have

$$
\left.\frac{d e_{H}}{d t_{H}}\right|_{d R^{H}=0,}=\frac{\left(w_{H}^{*}-e_{H}+\frac{t_{H} e_{H}}{w_{H}^{*}} \frac{\partial w_{H}^{*}}{\partial t_{H}}\right)}{\left(t_{H}-\frac{t_{H} e_{H}}{w_{H}^{*}} \frac{\partial w_{H}^{*}}{\partial e_{H}}\right)}>0 .
$$

Concerning the high-skilled wage effect of this reform we have $d w_{H}^{*}=\frac{\partial w_{H}^{*}}{\partial t_{H}} d t_{H}+\frac{\partial w_{L}^{*}}{\partial e_{H}} d e_{H}$. Dividing by $d t_{L}$ and substituting the RHS of (34) for $d e_{H} / d t_{L}$ gives

$$
\left.\frac{d w_{H}^{*}}{d t_{H}}\right|_{d R^{H}=0}=\frac{\left[\frac{\partial w_{H}^{*}}{\partial t_{H}}+\frac{\left(w_{H}^{*}-e_{H}\right)}{t_{H}} \frac{\partial w_{H}^{*}}{\partial e_{H}}\right]}{\left[1-\frac{e_{H}}{w_{H}^{*}} \frac{\partial w_{H}^{*}}{\partial e_{H}}\right]}=0 \text { for } \delta\left\{\begin{array}{l}
> \\
= \\
<
\end{array}\right] 1
$$

because the numerator is zero (see Appendix C) so that a higher degree of wage tax 
progression, keeping the relative tax burden per high-skilled worker constant, will have no effect on the high-skilled wage in the presence of CES and C-D utility function. Because there are no effect of high-skilled wage tax progression on highskilled and low-skilled wage in the case of different tax parameters compared with low-skilled workers, there is no employment effects in this case.

We can now summarize our findings regarding the properties of the domestic labor demand in the presence of flexible outsourcing as follows.

Proposition 5 In the presence of flexible outsourcing

(a) a higher degree of wage tax progression for the high-skilled worker , keeping the relative tax burden per high-skilled worker constant, will have no effect on the high-skilled wage in the presence of CES and C$D$ utility function, while

(b) this higher-degree of tax progression will have no employment effects.

\section{Conclusions}

Most western European countries are characterized by dual labour markets, in which wages of some workers are set by labour unions, while other wages are determined competitively. In this paper we have studied an economy in which unskilled workers form a monopoly labour union, while skilled workers are employed in competitive labour markets. We analyze how the presence of flexible outsourcing, which is decided after the unskilled wage is set by the monopoly labour union, affects such an economy.

It has been shown in the presence of flexible outsourcing both in the case of high-skilled workers' CES and in the case of C-D utility function in competitive labor market equilibrium (a) the high-skilled wage depends negatively on the lowskilled wage, whereas (b) the high-skilled wage depends positively (negatively) on the wage tax when the elasticity of substitution between consumption and leisure is higher (lower ) than one, whereas (c) the high-skilled wage depends negatively (positively) on the tax exemption when the elasticity of substitution between 
consumption and leisure is higher (lower) than one, while the high-skilled wage is independent of tax parameters under C-D utility function. Moreover both in the case of high- skilled workers' CES and C-D utility function in competitive labor market equilibrium higher outsourcing wage and higher outsourcing cost will increase the wage for the low-skilled labor because the wage elasticity of the low-skilled labor will decrease and they will decrease the wage for the high-skilled labor.

A higher low-skilled wage tax rate will increase the wage for the low-skilled labour and decrease the wage for high-skilled labour and the higher low-skilled wage tax exemption will decrease the wage for the low-skilled labour and will increase the wage for the high-skilled labour. Similar qualitative effects arise in the absence of outsourcing. In terms of labor tax reform (a) a higher degree of tax progression by raising the wage tax and the tax exemption for the low-skilled workers to keep the relative burden per low-skilled worker constant will decrease the wage rate and increase labour demand of low-skilled workers, whereas (b) it will decrease (increase) employment of high-skilled workers in CES utility function when the elasticity of substitution between consumption and leisure is higher (lower) than one, (c) while it will have no effect on employment of high-skilled workers in the case of C-D utility function of high-skilled workers.

Finally, it has been shown that a higher degree of wage tax progression for the high-skilled worker, keeping the relative tax burden per high-skilled worker constant, will have no effect on the high-skilled wage in the presence of CES and CD utility function. Because there are no effect of high-skilled wage tax progression on high-skilled and low-skilled wage in the case of different tax parameters compared with low-skilled workers, there is no employment effects in this case.

This framework suggests avenues for further research. I only focus on two new aspects. First, the resources that domestic firms spend on outsourcing will give rise to welfare effects in other countries. This suggests that uncoordinated policies might be inefficient from the perspective of society as a whole, and that outsourcing may provide an argument for policy coordination across countries. This has been studied by Aronsson and Sjögren (2004) in the absence of outsourcing. Second, it is also 
useful to study what are the implications of various tax reforms in the case of product market imperfections, whether due to monopolistic or oligopolistic competition.

\section{Appendix A: Optimal Low-skilled Wage Setting under Linearly Progressive Wage Taxation}

The first-order condition associated with $\underbrace{\max }_{\left(w_{L}\right)} V=\left(\hat{w}_{L}-b_{L}\right) L$ s.t. $\pi_{L}=0$ and $H^{*}=H^{s}$ can be written as follows

$$
V_{w_{L}}=\frac{L^{*}}{w_{L}}\left[\left(1-t_{L}\right) w_{L}+\left(\left(1-t_{L}\right) w_{L}+t_{L} e-b_{L}\right)\left(\frac{L_{w_{L}}^{*} w_{L}}{L^{*}}+\frac{L_{w_{H}}^{*} w_{H}}{L^{*}} \frac{d w_{H}}{d w_{L}} \frac{w_{L}}{w_{H}}\right)\right]=0
$$

where the own wage elasticity of the low-skilled labor demand is $\eta_{L}^{f}=\varepsilon_{L}^{L}\left(1+\gamma \frac{M^{*}}{L^{*}}\right)+\frac{\gamma}{L^{*}}\left(M^{*}+\frac{w_{M}}{c^{*}}\right)$ and the cross wage elasticity is $\eta_{H}^{f}=\varepsilon_{H}^{L}\left(1+\gamma \frac{M^{*}}{L^{*}}\right) \quad$ and the low-skilled labor demand is $L^{*}=m w_{L}^{-\varepsilon_{L}^{L}} w_{H}^{-\varepsilon_{H}^{L}}-\gamma M^{*}=m w_{L}^{-\varepsilon_{L}^{L}} w_{H}^{-\varepsilon_{H}^{L}}-\gamma\left(\frac{\gamma w_{L}-w_{M}}{c}\right)$. Equation (A1) can be expressed as equation (18) in the text.

$$
w_{L}^{*}=\left(\frac{\eta_{L}^{f}+\eta_{H}^{f} \frac{d w_{H} w_{L}}{d w_{L} w_{H}}}{\eta_{L}^{f}+\eta_{H}^{f} \frac{d w_{H} w_{L}}{d w_{L} w_{H}}-1}\right) \hat{b}_{L}
$$

In the case of the CES utility function we have

$$
w_{H}^{-\varepsilon_{H}^{H}}+\left(\frac{1-\alpha}{\alpha}\right)^{\delta} w_{H}^{1-\varepsilon_{H}^{H}-\delta}=\frac{(1-a)}{m a} w_{L}^{\varepsilon_{L}^{H}}
$$

so that

$$
\left.\frac{d w_{H}}{d w_{L}}\right|_{\delta \neq 1}=\frac{\varepsilon_{L}^{H} \frac{(1-a)}{m a} w_{L}^{\varepsilon_{L}^{H}-1}}{\left(-\varepsilon_{H}^{H} w_{H}^{-\varepsilon_{H}^{H}-1}+\left(\frac{1-\alpha}{\alpha}\right)^{\delta}\left[\left(1-t_{H}\right)\left(1-\varepsilon_{H}^{H}-\delta\right)-\varepsilon_{H}^{H} t_{H} e w_{H}^{-1}\right] w_{H}^{-\varepsilon_{H}^{H}} \hat{w}_{H}^{-\delta}\right)}<0
$$


where $1-\varepsilon_{H}^{H}-\delta<0$. Using (A3) and (A4) gives

$$
\begin{aligned}
\left.\frac{d w_{H}}{d w_{L}} \frac{w_{L}}{w_{H}}\right|_{\delta \neq 1}= & \frac{\varepsilon_{L}^{H} \frac{(1-a)}{m a} w_{L}^{\varepsilon_{L}^{H}}}{\left(-\varepsilon_{H}^{H} w_{H}^{-\varepsilon_{H}^{H}}+\left(\frac{1-\alpha}{\alpha}\right)^{\delta}\left[w_{H}\left(1-t_{H}\right)\left(1-\varepsilon_{H}^{H}-\delta\right)-\varepsilon_{H}^{H} t_{H} e_{L}\right] w_{H}^{-\varepsilon_{H}^{H}} \hat{w}_{H}^{-\delta}\right)} \\
= & \frac{\varepsilon_{L}^{H} w_{H}^{-\varepsilon_{H}^{H}}\left[1+\left(\frac{1-\alpha}{\alpha}\right)^{\delta} \hat{w}_{H}^{1-\delta}\right]}{-\varepsilon_{H}^{H} w_{H}^{-\varepsilon_{H}^{H}}\left[1+\left(\frac{1-\alpha}{\alpha}\right)^{\delta} \hat{w}_{H}^{1-\delta}-\left(\frac{1-\alpha}{\alpha}\right)^{\delta} w_{H}(1-\delta) \hat{w}_{H}^{-\delta}\right]}=-\frac{\varepsilon_{L}^{H}}{\varepsilon_{H}^{H}} \frac{T}{U}<0
\end{aligned}
$$

where $\quad T=1+\left(\frac{1-\alpha}{\alpha}\right)^{\delta} w_{H}^{1-\delta}>0 \quad$ and $\quad U=1+\left(\frac{1-\alpha}{\alpha}\right)^{\delta} \hat{w}_{H}^{-\delta}\left(t_{H} e+w_{H}\left(1-t_{H}\right) \delta\right)>0$. Therefore, we have the low-skilled wage decided by the monopoly labor union in the presence of high-skilled workers' CES and C-D utility functions

$$
\left.w_{L}^{*}\right|_{\delta \neq 1}=\left(\frac{\eta_{L}^{f}-\eta_{H}^{f} \frac{\varepsilon_{L}^{H}}{\varepsilon_{H}^{H}} \frac{T}{U}}{\eta_{L}^{f}-\eta_{H}^{f} \frac{\varepsilon_{L}^{H}}{\varepsilon_{H}^{H}} \frac{T}{U}-1}\right) \hat{b}_{L} \text { and }\left.w_{L}^{*}\right|_{\delta=1}=\left(\frac{\eta_{L}^{f}-\eta_{H}^{f} \frac{\varepsilon_{L}^{H}}{\varepsilon_{H}^{H}}}{\eta_{L}^{f}-\eta_{H}^{f} \frac{\varepsilon_{L}^{H}}{\varepsilon_{H}^{H}}-1}\right) \hat{b}_{L}
$$

where $\left.\frac{d w_{H}}{d w_{L}} \frac{w_{L}}{w_{H}}\right|_{\delta=1}=-\frac{\varepsilon_{L}^{H}}{\varepsilon_{H}^{H}}<0$. QED.

\section{Appendix B: Tax Progression and Low-skilled Labor Demand}

Substituting the RHS of (29) into $d w_{L}^{*}=\frac{\partial w_{L}^{*}}{\partial t_{L}} d t_{L}+\frac{\partial w_{L}^{*}}{\partial e} d e_{L}$ implies

$$
\left.\frac{d w_{L}^{*}}{d t_{L}}\right|_{d R=0}=\frac{\left(\frac{\partial w_{L}^{*}}{\partial t_{L}} t_{L}\left(1-\frac{e_{L}}{w_{L}^{*}} \frac{\partial w_{L}^{*}}{\partial e_{L}}\right)+\frac{\partial w_{L}^{*}}{\partial e}\left(w_{L}^{*}-e_{L}\right)+\frac{\partial w_{L}^{*}}{\partial e} \frac{t_{L} e_{L}}{w_{L}^{*}} \frac{\partial w_{L}^{*}}{\partial t_{L}}\right)}{t_{L}\left[1-\frac{e_{L}}{w_{L}^{*}} \frac{\partial w_{L}^{*}}{\partial e_{L}}\right]}
$$

which gives (30), where the denominator is positive. Concerning the numerator

$$
\begin{aligned}
\frac{\partial w_{L}^{*}}{\partial t_{L}}+\frac{\left(w_{L}^{*}-e_{L}\right)}{t_{L}} \frac{\partial w_{L}^{*}}{\partial e_{L}} \text { in (30) we obtain that it is negative, i.e. } & \\
& \frac{\partial w_{L}^{*}}{\partial t_{L}}+\frac{\left(w_{L}^{*}-e_{L}\right)}{t_{L}} \frac{\partial w_{L}^{*}}{\partial e}=\frac{B}{\left(1-t_{L}\right)^{2}}\left(b_{L}-\hat{w}_{L}\right)<0
\end{aligned}
$$


where

$$
B=\frac{\bar{\eta}_{L}^{f}}{\bar{\eta}_{L}^{f}-1+\frac{\partial \bar{\eta}_{L}^{f}}{\partial w_{L}} \frac{w_{L}}{\bar{\eta}_{L}^{f}}}>0 \quad \text { and } \quad b_{L}-\hat{w}_{L}=b_{L}-\left(w_{L}^{*}\left(1-t_{L}\right)+t_{L} e_{L}\right)<0 .
$$

Without outsourcing we have the same qualitative, but quantitatively different result, i.e.

$$
\left.\frac{d w_{L}^{*}}{d t_{L}}\right|_{d R=0, M=0}=\left[\frac{\partial w_{L}^{*}}{\partial t_{L}}+\frac{\left(w_{L}^{*}-e_{L}\right)}{t_{L}} \frac{\partial w_{L}^{*}}{\partial e}\right]_{M=0}=\frac{\bar{\varepsilon}}{(\bar{\varepsilon}-1)\left(1-t_{L}\right)^{2}}\left(b_{L}-\hat{w}_{L}\right)<0 . \text { QED. }
$$

\section{Appendix C: Tax Progression and High-skilled Labor Demand}

Using equations (15b-15c) and express the denominators as

$$
-\varepsilon_{H}^{H} w_{H}^{-\varepsilon_{H}^{H}-1}+\left(\frac{1-\alpha}{\alpha}\right)^{\delta}\left[\left(1-t_{H}\right)\left(1-\varepsilon_{H}^{H}-\delta\right)-\varepsilon_{H}^{H} t_{H} e_{H} w_{H}^{-1}\right] w_{H}^{-\varepsilon_{H}^{H}} \hat{w}_{H}^{-\delta}=X<0,
$$

we have

$$
\frac{\partial w_{H}^{*}}{\partial t_{H}}+\frac{\left(w_{H}^{*}-e_{H}\right)}{t_{H}} \frac{\partial w_{H}^{*}}{\partial e_{H}}=X^{-1}\left((1-\delta)\left(w_{H}-e_{H}\right)\left(\frac{1-\alpha}{\alpha}\right)^{\delta} w_{H}^{-\varepsilon_{H}^{H}} \hat{w}_{H}^{-\delta}\left(\frac{t_{H}-t_{H}}{t_{H}}\right)=0 .\right.
$$

QED.

\section{References:}

Aronsson, T. and T. Sjögren (2004): Efficient Taxation, Wage Bargaining and Policy Coordination, Journal of Public Economics, 88, 2711-2725.

Braun, F.D. and J. Scheffel (2007): Does International Outsourcing Depress Union Wages?, SFB 649 Discussion Paper, 2007-033, Humbold Universität zu Berlin.

Cahuc, P. and A. Zylberberg (2004): Labor Economics, the MIT Press.

Eckel, C. and H. Egger (2009): Wage Bargaining and Multinational Firms, Journal of International Economics, 77, 206-214.

Egger, H. and P. Egger (2006): International Outsourcing and the Productivity of Low-Skilled Labor in the EU, Economic Inquiry, 44, 98-108.

Ethier, W.J. (2005): Globalization, globalisation: Trade, Technology and Wages, International Review of Economics and Finance 14, 237-258.

Feenstra, R.C. and G.H. Hanson (1999): The Impact of Outsourcing and HighTechnology Capital on Wages: Estimates for the United States, 1979-1990, Quarterly Journal of Economics, 114, 907-940. 
Feenstra, R.C. and G.H. Hanson (2003): Global Production Sharing and Rising Inequality: A Survey of Trade and Wages, NBER Working Paper No. 8372, published in: Kwan Choi, E. and J. Harrigan (2003) (eds): Handbook of International Trade, Blackwell Publishing Ltd, 146-185.

Geischecker, I. and H. Görg (2008): Winners and Losers: A Micro-Level Analysis of International Outsourcing and Wages, Canadian Journal of Economics, 41, 243-270.

Görg, H. and A. Hanley (2005): Labor Demand Effects of International Outsourcing: Evidence from Plant-Level Data, International Review of Economics and Finance, 14, 365-376.

Hasan, R., D. Mitra and R.V. Ramaswamy (2007): Trade Reforms, Labor Regulations, and Labor-Demand Elasticities: Empirical Evidence from India, the Review of Economics and Statistics, 89(3), 466-481.

Hijzen, A. (2007): International Outsourcing, Technological Change, and Wage Inequality, Review of International Economics, 15, 188-205.

Hijzen, A., H. Görg and R.C. Hine (2005): International Outsourcing and the Skill Structure of Labor Demand in the United Kingdom, the Economic Journal, 115, 860-878.

Koskela, E. and R. Schöb (2002): Optimal Factor Income Taxation in the Presence of Unemployment, Journal of Public Economic Theory, 4, 387-404.

Koskela, E. and R. Schöb (2009): Outsourcing of Unionized Firms and the Impact of Labour Market Policy Reforms, IZA Discussion Paper No. 3566, University of Bonn, forthcoming in: Review of International Economics.

Koskela, E. and R. Stenbacka (2009): Equilibrium Unemployment with Outsourcing and Wage Solidarity under Labour Market Imperfections, article in press in: European Economic Review.

Koskela, E. and J. Vilmunen (1996): Tax Progression is Good for Employment in Popular Models of Trade Union Behaviour, Labour Economics, 3, 65-80.

Lambert, P.J. (2001): The Distribution and Redistribution of Income, $3^{\text {rd }}$ edition, Manchester University Press.

Munch, J.R. and J.R. Skaksen (2009): Specialization, Outsourcing and Wages, Review of World Economics, 145, 57-73.

Musgrave, R.A. and T. Thin (1948): Income Tax Progression, 1929-1948, Journal of Political Economy, 56, 498-514. 
Riley, R. and G. Young (2007): Skill Heterogeneity and Equilibrium Unemployment, Oxford Economic Papers, 59, 702-725.

Sinn, H.-W. (2007): The Welfare State and the Forces of Globalization, CESifo Working Paper No. 1925.

Skaksen, J.R. (2004): International Outsourcing When Labor Markets are Unionized, Canadian Journal of Economics, 37(1), 78-94.

Slaughter, M.J. (2001): International Trade and Labor-Demand Elasticities, Journal of International Economics, 54, 27-56.

Stefanova, B.M. (2006): The Political Economy of Outsourcing in the European Union and the East-European Enlargement, Business and Politics 8, issue 2. 